Bangladesh J. Plant Taxon. 19(1): 45-53, 2012 (June)

(C) 2012 Bangladesh Association of Plant Taxonomists

\title{
ETHNO-MEDICO BOTANICAL STUDY AMONG THE FOUR INDIGENOUS COMMUNITIES OF BANDARBAN, BANGLADESH
}

\author{
Mohammed Mohiuddin ${ }^{1}$, Md. Khairul Alam, Sukla Rani Basak \\ AND M. KAMAL HoSSAIN ${ }^{2}$ \\ Forest Botany Division, Bangladesh Forest Research Institute, Sholoshahar, \\ P.O. Box -273, Chittagong 4000, Bangladesh
}

Keywords: Medicinal plants; Ethnobotany; Indigenous knowledge; Bandarban.

\begin{abstract}
This paper provides ethno-botanical information on 70 plant species under 36 families and these species were in common use among the Bwam, the Marma, the Murang and the Tanchangya communities of Bandarban hill district. Ethno-medicinal uses along with their scientific names, families, local names, voucher numbers and uses are enumerated. Quantitative analysis shows that the Marma tribe uses the higher number of species followed by the Tanchangya, the Murang and the Bwam. Similarity index indicates that the Marma, the Tanchangya and the Murang have higher similarities for ethno-botanical knowledge among four tribes. The most widely used medicinal plants are Cassia obtusifolia L., Centella asiatica (L) Urban., Costus speciosus Smith, Emilia sonchifolia DC., Litsea glutinosa (Lour.) Roxb., Melothria indica Lour. and Premna esculenta Roxb. Fever, cough, menstrual problem, diarrhoea, dysentery, tumor and skin diseases seem to be common problems treated using plants by the tribal communities in Bandarban district.
\end{abstract}

\section{Introduction}

Bandarban hill district is the second largest district of Chittagong Hill Tracts (CHT) with an area of 4,502 sq. km. It is situated in the southeast of Bangladesh and located between $21^{\circ} 25^{\prime}$ and $23^{\circ} 45^{\prime} \mathrm{N}$ and between $91^{\circ} 45^{\prime}$ and $92^{\circ} 50^{\prime} \mathrm{E}$ (Alam and Mohiuddin, 2008). Geographically it is a part of the Hindu-Kush-Himalayan region of the continent (Khan et al., 2007). Landform of Bandarban is mainly composed of high hills (20\%), medium hills (22\%), low hills (31\%) and the rest is valley land. Eleven tribes (ethnic groups) are living in different hilly areas of Bandarban district (Banglapedia, 2006). The Bwam, the Marma, the Murang, and the Tanchangya are the dominant tribes and constitute $70 \%$ hill population of this district (Khan et al., 2007). They have their own culture, tradition and primary health care system acquired through close observation of nature. These tribal people has a close relation with surrounding flora and using different plant parts as food, medicine, dye, soap and other purposes from the time immemorial in their day to day life.

Bandarban district is rich in floristic composition of medicinal plants, and the tribal herbal healers locally called "Bhaidya" use these plants in preparing traditional medicine. Ethnomedicinal knowledge plays an important role in identifying plants of therapeutic agents (Balick, 1990). Ethno-botanical samples contain novel drug compounds and helps to find out economically important plant based drugs (Cox and Balick, 1994). Like the other parts of the world, a good number of the people of Bandarban hill district still depend upon the herbal healers and herbal medicine for treatments.

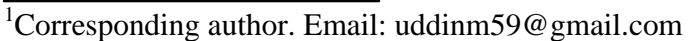

${ }^{2}$ Institute of Forestry and Environmental Sciences, University of Chittagong, Chittagong, Bangladesh.
} 
Several ethno-medicinal studies in Bangladesh have been carried out by Alam (1992), Hassan and Khan (1996), Rahman et al. (1998), Rahman and Uddin (1998), Rahman (2003), Rahman et al. (2003), Uddin et al. (2004) and Yusuf et al. (2006, 2007). However, there is very limited information on the ethno-medicinal plants used by the tribal communities of Bandarban hill district. This study aims to document ethno-medicinal plants used for the treatment of different diseases by four tribes of Bandarban district namely the Bwam, the Marma, the Murang, and the Tanchangya communities to make a quantitative analysis of botanical knowledge of these tribes.

\section{Materials and Methods}

A series of exploration in the tribal areas of Bandarban district have been conducted for a period of four years through 2003 to2007. During the study we visited different tribal paras (villages) of three Upazillas namely Bandarban Sadar, Lama and Rwangcharai during different seasons for collecting the ethnomedicinal plants. The Marma and the Tanchangya tribes have herbal healers, locally called 'Bhaidya'. The other two tribes (the Bwam and the Murang) generally do not have herbal healers. For the study we collected plant specimens in different seasons along with necessary information with the help of herbal healers from the surrounding forests areas. Collated information was cross checked in the field to validate the gathered information. Collected samples were processed and authentically identified consulting the pertinent literatures, viz. Hooker (1872-1897), Prain (1903), Brandis (1906) and Kanjilal et al. (1934, 1938, 1939, 1940). The voucher specimens are housed in Bangladesh Forest Research Institute Herbarium, Chittagong. In this paper the common species between and among the four tribes have been enumerated. Local names are given in italics followed by the tribal name in parenthesis in abbreviated form (B for Bwam, $\mathrm{M}$ for Marma, $\mathrm{Mu}$ for Murang and $\mathrm{T}$ for Tanchangya). Prior consent of the knowledge providers were taken for documentation and further sharing.

\section{Results and Discussion}

The plants used by four tribes in Bandarban district are summarized in Table 1. A comparative analysis of the number of ethno-medicinal plants used by the four tribes showed that the Marma tribe uses the highest number of species (48 species), followed by the Tanchangya (43 species), the Murang (34 species) and lowest by the Bwam (6 species). Costus speciosus, Emila sonchifolia and Prema esculenta were common among the four tribes. Alpinia nigra, Cassia obtusifolia, Centella asiatica, Emblica officinalis, Melthoria indica, Sarcochlamys pulcherrima, Solanum torvum and Spilanthes calva were common species among the Marma, the Murang and the Tanchangya. Similarity index showed that 29 species were common between Tanchangya and Marma, 25 species were common between Murang and Marma, 9 species were common between Tanchangya and Murang (Table 2). Six species were common for Bwam and Marma. Five species were common for Bwam and Murang. Three species were common for Tanchangya and Bwam. The present findings indicated that the plant use pattern by different tribes is different, and number of common species used by different tribes is very limited. Use of more plants by the Marma tribe for different purposes indicates that they have more knowledge-base about the plant use than other three tribes. 


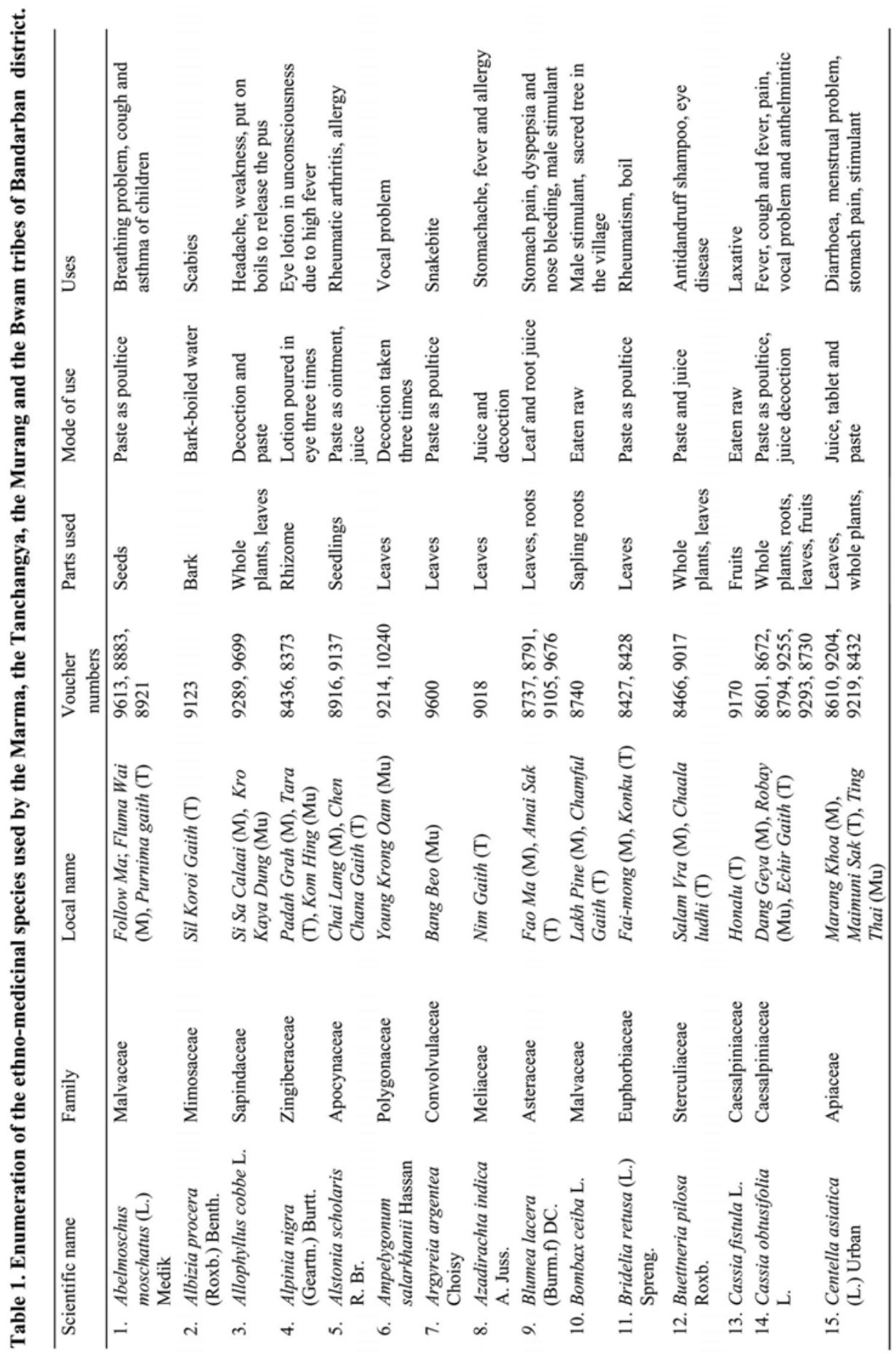




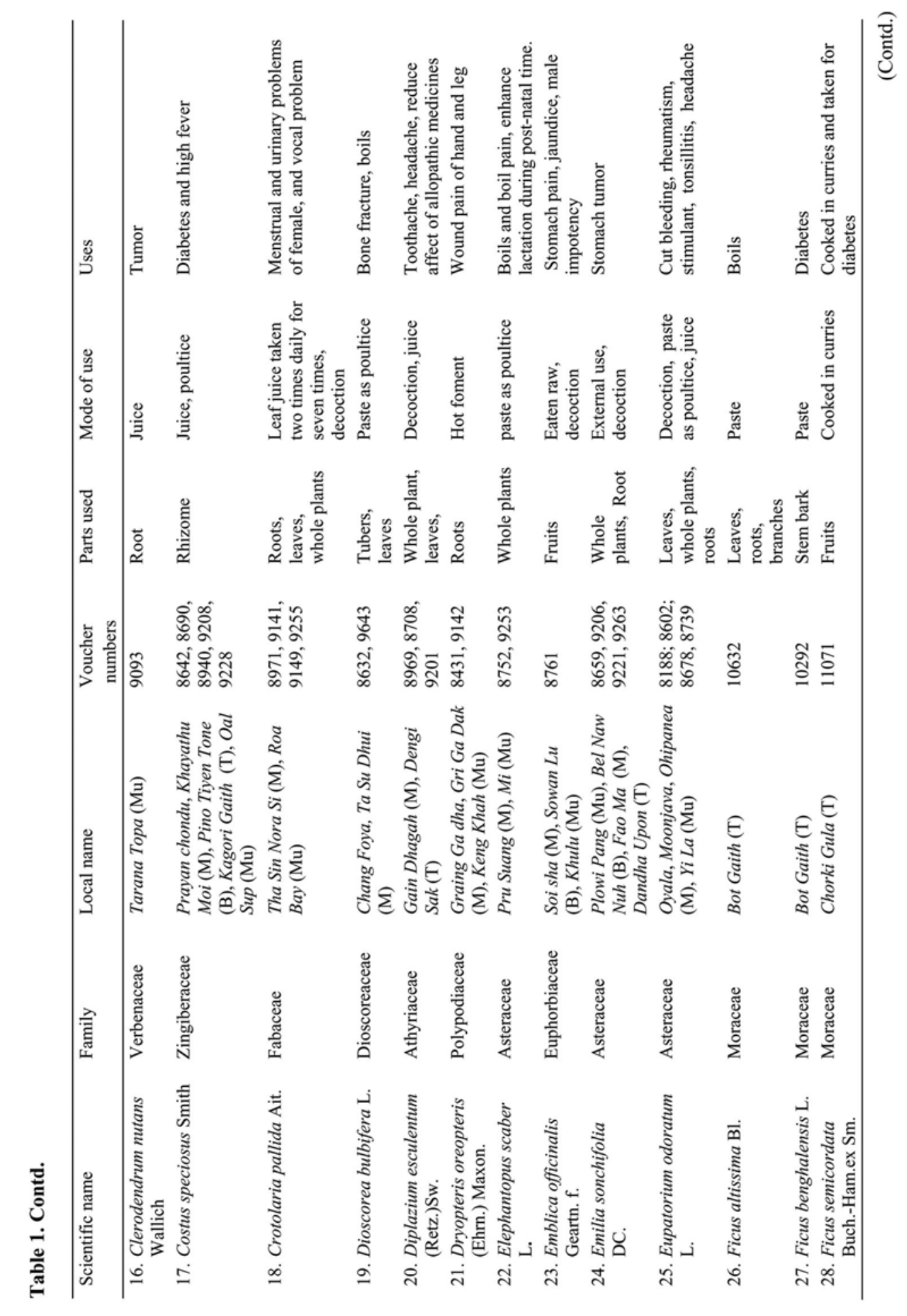




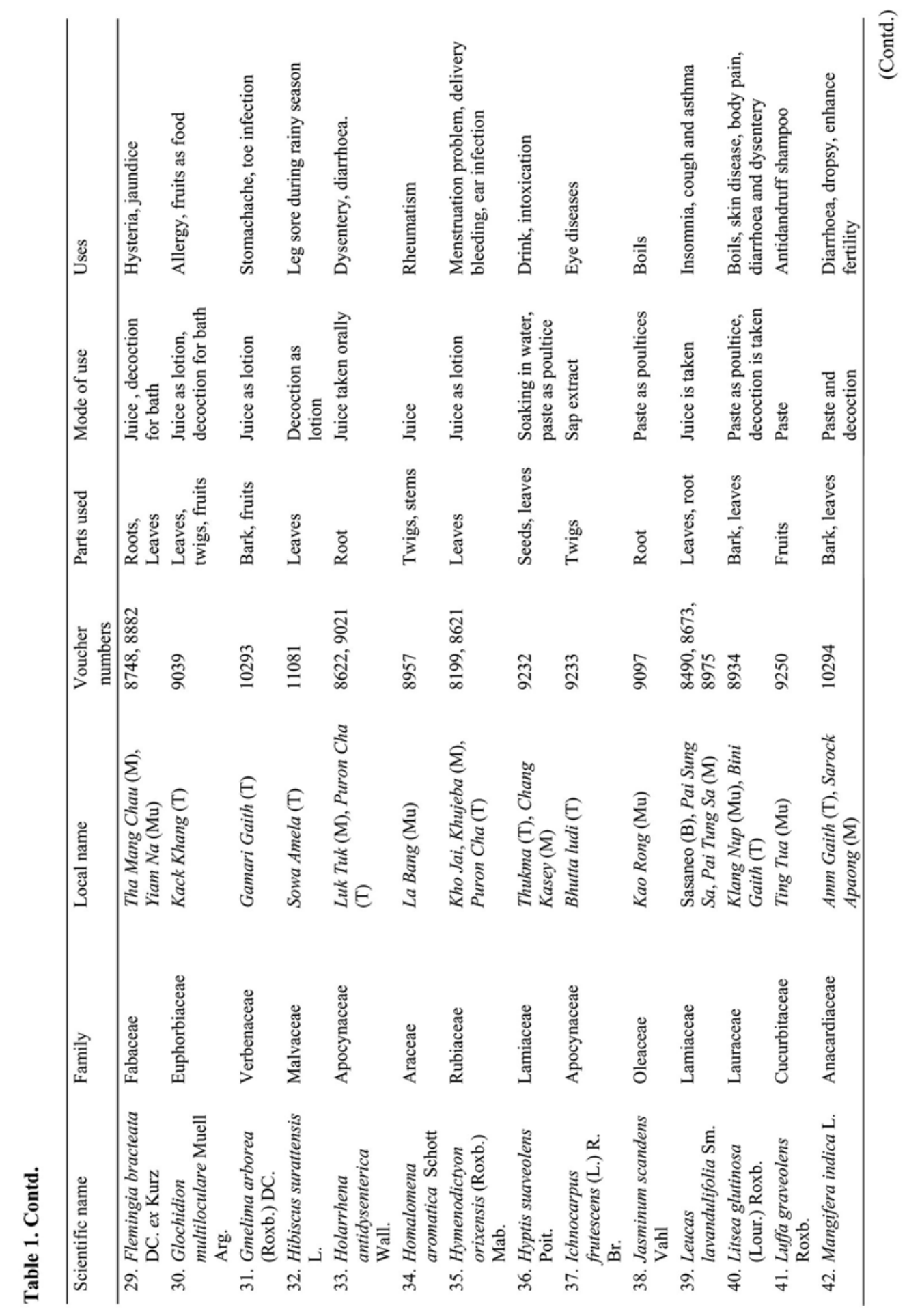




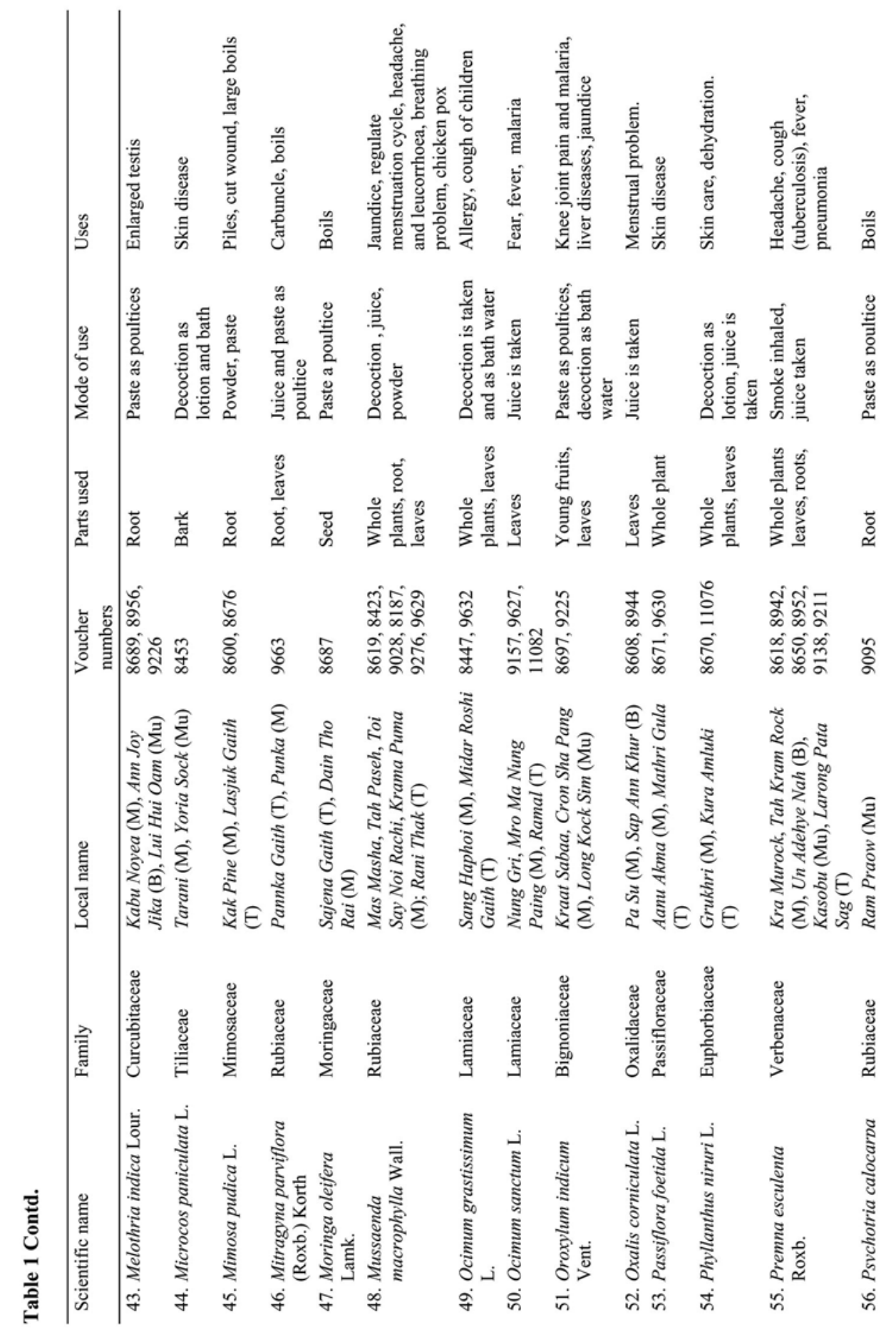




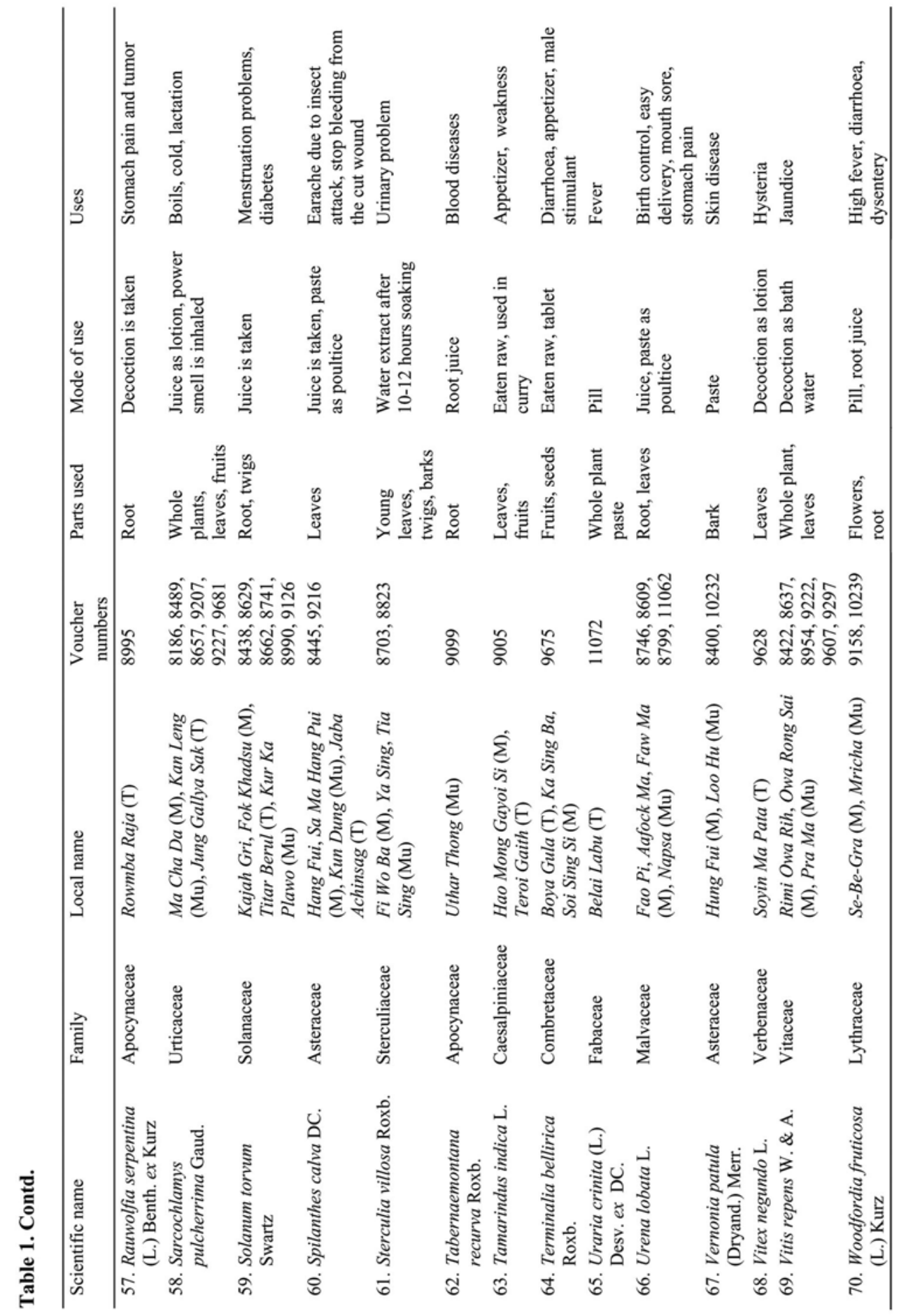


Table 2. Similarity index of common medicinal plant species among the four tribes in Bandarban.

\begin{tabular}{lcccc}
\hline Tribes & Marma & Tanchangya & Murang & Bwam \\
\hline Marma & 0 & & & \\
Tanchangya & 29 & 0 & & \\
Murang & 25 & 9 & 0 & \\
Bwam & 6 & 3 & 5 & 0 \\
\hline
\end{tabular}

\section{Acknowledgement}

We are thankful to the local healers and other informants who kindly had provided us with this valuable information and allowed us to document it.

\section{References}

Alam, M.K. 1992. Medicinal ethnobotany of the Marma tribe of Bangladesh. Economic Botany 46(3): 330335.

Alam, M.K. and Mohiuddin, M. 2008. Shifting cultivation (Jhum) agrobiodiversity at stake: Bangladesh Situation. Acta Hort. 806(2): 709-715.

Balick, J.M. 1990. Ethnobotany and identification of therapeutic agents from the rainforest. In: Chadwick, D.J. and Marsh J. (eds), Ethnobotany and the Search for New Drugs (Ciba Foundation Symposium 185). Wiley, Chi Chester, pp. 22-32.

Banglapedia 2006. Bandarban district. Asiatic Society of Bangladesh, Dhaka. Website: <www.banglapedia. org/httpdocs/HT/B - 0101 HTM>.

Brandis, D. 1906 (Reprint 1978). Indian Trees. Periodical Expert Book Agency, Delhi, India, 677 pp.

Cox, P.A. and Balick, M.J. 1994. The ethnobotanical approach to drug discovery. Sci. Amer. 270(6): 60-65.

Hassan, M.A. and Khan, M.S. 1996. Ethnobotanical records in Bangladesh -2. Plants used for healing cuts and wounds. Bangladesh J. Plant Taxon. 3(2): 49-52.

Hooker, J.D. 1872-1897. Flora of British India, Vols. 1-7. Reeve \& Co., Kent, England.

Kanjilal, U.N., Kanjilal, P.C. and Das, A. 1934. (Reprint1984). Flora of Assam. 1: 1-386. Periodical Expert Book Agency, Delhi.

Kanjilal, U.N., Kanjilal, P.C. and Das, A. 1938. (Reprinted 1984). Flora of Assam. 2:1-409 Periodical Expert Book Agency, Delhi.

Kanjilal, U.N., Das, A. Kanjilal, P.C. and De, R.N. 1939. (Reprint 1982). Flora of Assam. 3: 1-578. A Von Book Co., Delhi.

Kanjilal, U.N., Das, A. Kanjilal, P.C. and De, R.N. 1940. (Reprint1984). Flora of Assam. Vol. 4: 1-377. A Von Book Co., Delhi.

Khan, M.F.A., Mantel, S. and Chowdhury, E.H. 2007. State of the Environment of the Chittagong Hill Tracts. Charm Project Report 2. (Pro.no. BD/Asia-pro Eco/12/103-584).

Prain, D. 1903. (Indian Reprint 1981). Bengal Plants. 1\&2: 1-1319. Bishen Singh Mahendra Pal Singh, Dehra Dun, India.

Rahman M.A. 2003. Ethno-medico-botanical knowledge among tribals of Bangladesh. In: Ethnobotany and Medicinal Plants of Indian Subcontinent. Scientific Publisher, Jodhpur, India, pp. 89-93.

Rahman, M.A. and Uddin, S.B. 1998. Some anti-rheumatic plants used by tribal people of Hill Tracts districts of Bangladesh. Biodiversity Newsletter 2(2): 4.

Rahman, M.A., Uddin, S.B. and Khisa, A. 1998. A report on some anti-Jaundice plants from tribal community of Hill districts. Biodiversity Newsletter 2(1): 4. 
Rahman, M.A., Uddin, S.B. and Wilcock, C.C. 2003. Indigenous knowledge of herbal medicine in Bangladesh: Diarrhoea, dysentery, indigestion and stomach pains. J. Med. \& Aro. Pl. Sc. 25: 101-109.

Uddin, S.N., Uddin, M.Z., Hassan, M.A. and Rahman, M.M. 2004. Preliminary ethnobotanical plant survey in Khagrachari district, Bangladesh. Bangladesh J. Plant Taxon. 11(2): 39-48.

Yusuf, M., Wahab, M.A. and Chowdhury J.U. 2006. Ethno-medico-botanical knowledge from Kauhkali Proper and Betbunia of Rangamati District. Bangladesh J. Plant Taxon. 13(1):55-61.

Yusuf, M., Wahab, M.A., Yousuf, M., Chowdhury, J.U. and Begum, J. 2007. Some tribal medicinal plants of Chittagong Hill Tracts, Bangladesh. Bangladesh J. Plant Taxon. 14(2): 117-128.

(Manuscript received on 6 July, 2011; revised on 12 April, 2012) 